\title{
TENSÃO E PRODUÇÃO DE SENTIDOS EM BAKHTIN E O CÍRCULO
}

\author{
TENSION AND MEANING MAKING TENSIÓN Y PRODUCCIÓN DE \\ IN BAKHTIN AND THE CIRCLE SIGNIFICADO EN BAKHTIN Y EL CÍRCULO
}

\author{
Paulo Rogério Stella* \\ Universidade Federal de Alagoas, Faculdade de Letras, Maceió, AL, Brasil \\ Beth Brait** \\ Pontifícia Universidade Católica de São Paulo, Faculdade de Filosofia, Comunicação e Artes, \\ Departamento de Ciências da Linguagem e Filosofia, São Paulo, SP, Brasil
}

\begin{abstract}
Resumo: Este artigo discute o sentido de tensão com base nos conceitos de compreensão e avaliação em Bakhtin e o Círculo, considerando que os sentidos se constroem no encontro de dois polos opostos, como uma faísca elétrica (VOLÓCHINOV, 2017). Perguntas de pesquisa: O que é tensão como reflexão teórica? Quais são os possíveis pontos de tensão, considerando compreensão e avaliação nos textos selecionados das obras de Bakhtin e o Círculo? Coletados os dados em artigos de periódico acadêmico especializado, em três obras é constatada a recorrência dos conceitos sob análise. As reflexões e definições teóricas apontam para dois centros de circulação de valores em embate. Quanto aos resultados obtidos, compreensão e avaliação, dois centros de valores, atuam como duplo um do outro na preparação de uma resposta ativa por parte de um locutor.
\end{abstract}

Palavras-chave: Tensão. Compreensão. Avaliação. Produção de sentidos.

\begin{abstract}
This paper discusses the meaning of tension based on Bakhtin and The Circle's concepts of comprehension and evaluation, considering that the construction of the meanings occurs in the encounter of two opposite poles, as an electric spark (VOLOSHINOV, 2017 [1973]). The research questions are two: what is tension as a theoretical reflection? What are the possible tension points when considering comprehension and evaluation in the texts selected among the works of Bakhtin and The Circle? After the data collection phase in papers of a specialized journal, we noticed three works in which we verified a recurrence of the concepts analyzed. Theoretical definitions and reflections about the meaning of tension lead to two centers of circulation of clashing values. Concerning the outcome of this research, comprehension and evaluation (two centers of value) act as a double of each other in the preparation of an active response by a speaker.
\end{abstract}

Keywords: Tension. Comprehension. Evaluation. Production of meanings.

Resumen: Este artículo discute el significado de tensión desde los conceptos de comprensión y evaluación en Bakhtin y el Círculo, considerando que los significados se construyen mediante el enganche de dos

\footnotetext{
* Docente na Faculdade de Letras (FALE), Universidade Federal de Alagoas - UFAL; Maceió, Alagoas, Brasil. Pós-doutorando do LAEL (PUCSP) no período compreendido entre 01/09/2019 a 31/08/2020. ORCID: https://orcid.org/0000-0003-4494-6319. E-mail: prstella@gmail.com.

** Docente nos Programas de Estudos Pós-Graduados em Linguística Aplicada e Estudos da Linguagem/LAEL e Literatura e Crítica Literária/LCL da PUCSP. Bolsista CNPq 1A, Proc. 307028/2018-6. ORCID: https://orcid.org/0000-0002-1421-0848. E-mail: bbrait@uol.com.br.
} 
terminales, como una chispa eléctrica (VOLOSHINOV, 1976). Preguntas de investigación: ¿cuál es el significado de la tensión como reflexión teórica? ¿Cuáles son los posibles puntos de tensión, considerando la comprensión y evaluación en textos seleccionados entre las obras de Bakhtin y el Círculo? Luego de realizar la fase de recolección de datos en una revista especializada, se obtuvieron tres trabajos en los que se verifican que los conceptos bajo análisis eran los más frecuentes. Las reflexiones y definiciones teóricas apuntan a dos focos de circulación de valores en conflicto. En cuanto a los resultados obtenidos, comprensión y evaluación, dos centros de valores, actúan como un doble entre sí en la preparación de una respuesta activa por parte de un locutor.

Palabras clave: Tensión. Comprensión. Evaluación. Producción de significado.

O que a palavra manifesta, o que ela torna evidente para uma comunidade de sujeitos que a ouvem, é o útil e o nocivo, e consequentemente, o justo e o injusto

(RANCIÈRE, 1996, p. 17).

A parresía portanto põe em risco não apenas a relação estabelecida entre quem fala e aquele a quem é dirigida a verdade, mas, no limite põe em risco a própria existência daquele que fala (FOUCAULT, 2017, p. 12-3).

Porque a nossa própria ideia - seja filosófica, científica, artística - nasce e se forma no processo de interação e de luta com os pensamentos dos outros, e isso não pode deixar de encontrar os seus reflexos também nas formas de expressão verbalizada de nosso pensamento. (BAKHTIN, 2016, p. 59)

\section{INTRODUÇÃO}

Sabemos que a palavra constitui um terreno de disputa entre, pelo menos, dois participantes em processo de interlocução. A palavra orientada a outros pode provocar reações as mais diversas, tornando-se quase impossível a previsão de todas as variações responsivas possíveis. Dizer alguma coisa a alguém implica certo grau de incerteza, e certa cumplicidade entre os interlocutores no compartilhamento de uma informação. Embora o locutor tenha sempre em mente seu auditório previsto, quando na produção do enunciado, visto que o dialogismo é constitutivo de todas as relações permeadas pela palavra, não há garantias de que a produção de sentidos visada pelo locutor chegue a seu auditório como inicialmente prevista.

Isto se dá em decorrência do fato de que a palavra, prenhe de sentidos, torna-se, segundo Volóchinov (2017), uma arena de disputas de posições opostas e, consequentemente, de sentidos divergentes entre "participantes do enunciado" (VOLÓCHINOV, 2019, p. 128) que, posicionados em seus tempos e espaços, direcionam seus olhares para além de seus interlocutores visados porque o campo de visão de cada um em relação ao outro é muito mais amplo do que apenas a imagem solitária desse outro a quem a palavra é orientada. Aquele para quem a palavra orienta-se, em um primeiro instante, não tem acesso ao campo de visão total do outro, de onde a palavra originou-se. Nem este, quando se torna respondente ativo, tem o ângulo de visão coincidente com aquele, a quem a palavra foi orientada primeiramente no instante da resposta. Volóchinov utiliza o termo "antipalavra" (2017, p. 232) para enfatizar esse embate de sentidos em que se inserem os interlocutores no instante único da produção de um enunciado concreto. 
Este artigo propõe reflexões acerca do embate de pontos de vista, entendido como um tenso processo de construção de sentidos que ocorre "no processo de interação social entre os participantes do enunciado" (VOLÓCHINOV, 2019, p. 128), isto é, nas várias manifestações concretas da palavra que a "transforma em verdadeira ou mentirosa, infame ou nobre, necessária ou inútil" (VOLÓCHINOV, 2019, p. 128), ou que "atribui à palavra seu significado artístico, tornando-a maravilhosa ou disforme" (VOLÓCHINOV, 2019, p. 128). Partimos da afirmação presente em Volóchinov (2017) acerca da relação dialógica estabelecida entre interlocutores quando no tratamento da significação.

Segundo Volóchinov (2017, p. 233), a significação "é uma faísca elétrica surgida apenas durante o contato de dois polos opostos". Em primeiro lugar, na produção de sentidos há a necessidade de se considerar certa tensão ocorrida como consequência desse contato entre os dois polos opostos. E, em segundo lugar, há também a necessidade de observar que a significação produzida desse encontro, essa faísca elétrica produzida por esse contato, pode não chegar aos participantes da mesma maneira, porque, na verdade, quando dois polos opostos se chocam, muitas faíscas são produzidas ao mesmo tempo, o que torna muito complexo o processo de significação.

Para este artigo, refletiremos acerca de tensão, focalizando os conceitos de compreensão e avaliação e seus desdobramentos presentes em Bakhtin $(2015,2016)$ e em Volóchinov (2017). A justificativa para a seleção dessas obras, capítulos e conceitos utilizados está descrita na próxima seção, em que trataremos especificamente do recorte proposto. Torna relevante passarmos em revista esse conjunto de textos em decorrência da grande circulação em artigos científicos nos últimos anos.

Para direcionar nosso olhar com respeito ao sentido de tensão, estabelecemos duas perguntas de pesquisa: o que é tensão como reflexão teórica? Quais são os possíveis pontos de tensão considerando-se compreensão e avaliação nos textos selecionados das obras de Bakhtin e o Círculo? Sabemos que existe tensão em todas as reflexões advindas de Bakhtin e o Círculo, pois, como arena de lutas (VOLÓCHINOV, 2017), a palavra - o discurso - concentra sempre, minimamente, dois feixes de sentido, dois pontos de vista distintos e, às vezes conflitantes, sobre o mesmo objeto. Além disso, coerentemente com a perspectiva dialógica de Bakhtin e o Círculo, os conceitos tendem a pequenos deslocamentos de sentido dependendo do local e do momento em que circulam nas obras, dialogando com o espaço e o tempo em foram produzidos e segundo o olhar situado do autor.

$\mathrm{Na}$ tentativa de controlar momentaneamente essa fluidez teórica e articular os conceitos tratados de forma coerente, de maneira a fazer sentido como perspectiva de pesquisa, dividimos este artigo em três partes, além desta introdução, das considerações finais e das referências ao final. A seção 2, intitulada Recortes, apresenta brevemente o caminho teórico-metodológico que guia nosso estudo, além de tratarmos dos parâmetros estabelecidos para o recorte utilizado e das razões pelas quais os textos utilizados nesta reflexão foram selecionados. A seção 3, intitulada Tensão, faz um breve percurso teórico de sentido visando ao entendimento do termo tensão. A seção 4, intitulada Compreensão e avaliação, trata especificamente da observação da circulação do sentido de tensão no que diz respeito à compreensão e avaliação especificamente nos textos selecionados. 
Para Agamben (2009), as metodologias de pesquisa servem para estabelecer uma ponte entre o pesquisador e os objetos do mundo. Sendo construções humanas situadas em um tempo e espaço específicos, as metodologias permitem reutilização, desde que o pesquisador faça os devidos deslocamentos, apropriando-se delas de modo a funcionarem como mediadoras em outros tempos e espaços.

Sousa Santos (2008) compartilha desta mesma perspectiva, dizendo que a simples reprodução de metodologias, criadas para funcionarem em situações específicas de países considerados centrais, não conseguem dar respostas adequadas às demandas sociais localizadas em países periféricos. A transposição de metodologias de pesquisa científica de um centro a outro, sem o devido questionamento acerca da viabilidade e das consequências desse processo no contexto local onde o método será utilizado, favorece a manutenção do status quo. O pesquisador deve encontrar alternativas metodológicas para o fazer científico, levando em consideração as necessidades e os conhecimentos adquiridos localmente. As metodologias replicáveis, normalmente decorrentes de uma ciência dita neutra ou apolítica, que visam à generalização de resultados, favorecem um processo contínuo de exclusão de saberes locais em decorrência do apagamento da possibilidade de manifestação dos valores localizados em favor de valores transplantados.

Grosfoguel (2013), por sua vez, critica o uso de metodologias generalizantes, estruturadas e reproduzíveis, dizendo que essas metodologias refletem especificamente o pensamento cartesiano, resultado de acontecimentos históricos ocorridos no mundo ocidental na formação da modernidade que ocasionaram mudanças ne percepção acerca do outro. Essas mudanças de percepção tiveram como consequência o apagamento de formas de saber localizados em favor de valores homogeneizantes decorrentes de um ponto de vista classificatório e paradigmático com base no homem branco, centroeuropeu, heterossexual, de elevada instrução formal. Os acontecimentos a que se refere o autor foram a expulsão dos árabes muçulmanos da Andaluzia, a queima de mulheres por bruxaria, a conquista das Américas e o transplante de populações negras da África para servirem como escravos.

A expulsão dos árabes muçulmanos da Andaluzia foi marcada pelo genocídio físico e cultural dos povos muçulmanos e judeus, o que ocasionou o apagamento das formas de produção de conhecimento islâmicos e judeus em favor de uma única forma de conhecimento considerada digna e aceitável: a europeia, espanhola e católica. A isso junta-se a morte de mulheres, acusadas de bruxaria no continente europeu, que acumulavam um conhecimento da história e da natureza ao redor, transmitido oralmente de geração para geração por meio de poesias e parlendas. Carecendo de organização formal, rigidez e neutralidade, essa forma de produção de conhecimentos afrontava diretamente os parâmetros metodológicos para a construção do saber do que viria a se constituir como ciência moderna com seu rigor e método.

A conquista das Américas, por sua vez, marcada pelo encontro do europeu com o radicalmente outro, ocasionou o surgimento da dúvida acerca da condição humana dos conquistados. Para tanto, estabeleceram-se paradigmas classificatórios com base em diferenças raciais a partir do paradigma: homem branco, centro-europeu, o que permitiu 
classificações como raça superior e raça inferior. Esse estabelecimento paradigmático abriu espaço para a transferência de pessoas do continente africano para o trabalho escravo no continente americano. As categorias humanas entendidas como desvios do paradigma vigente eram vistas como inferiores ou defeituosas, permitindo não somente a dominação e a exploração, mas também o apagamento de identidades culturais e raízes históricas. Esses quatro movimentos históricos têm seus resquícios nas metodologias que se dizem neutras e generalizáveis.

Morin (1991) oferece-nos uma alternativa para pensar metodologias alternativas por meio da aceitação das incertezas, emoções e motivações do pesquisador durante a construção do caminho da pesquisa. A inclusão da instabilidade metodológica dissolve a rigidez, que é típica dos métodos controlados e generalizantes, transformando o pensamento científico em um campo de possibilidades de produção de conhecimentos em que a reflexão científico-metodológica deve ser constantemente retomada, adaptando-se aos novos tempos e espaços. Uma metodologia desse tipo deve ser permeada pelo diálogo posicionado entre pesquisador e seu objeto de pesquisa, o que permite que ambos evoluam à medida que interagem como interlocutores.

Levando esses pressupostos em consideração, sem desmerecer a importância da metodologia como mediadora de reflexões entre o pesquisador e o objeto de discussão, estabelecemos os seguintes parâmetros para o recorte de pesquisa, especialmente para este artigo: 1. As obras de Bakhtin e o Círculo que circulam no meio acadêmico devem ter uma frequência de referenciação, isto é, algumas devem ser mais utilizadas do que outras; 2. A maneira de verificarmos a circulação das obras é por meio de referências em trabalhos acadêmicos relacionados à área de línguas e/ou discurso; 3. Artigos científicos podem ser uma boa fonte de observação, pois refletem tanto resultados de pesquisas quanto pesquisas em andamento. Levando-se isso em consideração, estabelecemos como ponto de observação os últimos três anos de circulação do periódico Bakhtiniana. Revista de Estudos do Discurso. As razões para esta escolha são, primeiramente, o fato de ser "o único periódico que contempla os estudos bakhtinianos no Brasil e no estrangeiro de forma específica e em seu diálogo com outras áreas do conhecimento"1; e, também, porque "tem como missão promover e divulgar pesquisas produzidas no campo dos estudos do discurso, com destaque para os estudos dialógicos ${ }^{2}$ ".

Por concentrar, parcial ou totalmente, artigos cujas reflexões, em sua maioria, têm como referencial teórico o pensamento de Bakhtin e o Círculo, podemos ter pistas acerca da aceitação e da circulação das obras de Bakhtin e o Círculo no pensamento acadêmico, o que pode nos ajudar a decidir acerca dos recortes feitos para este artigo. Objetivando a construção de um quadro relativamente atualizado, estipulamos o período de 2017 a 2020 ,

\footnotetext{
${ }^{1}$ Página de apresentação do periódico em: https://revistas.pucsp.br/bakhtiniana/about/editorialPolicies\#focusAndScope. Acesso em mar. 2020.

2 Página de apresentação do periódico em: https://revistas.pucsp.br/bakhtiniana/about/editorialPolicies\#focusAndScope. Acesso em mar. 2020.
} 
correspondendo aos volumes 12 a $15^{3}$ do periódico ${ }^{4}$. Nesses volumes, descontando resenhas de livros e entrevistas com pesquisadores, encontramos 76 artigos, publicados em língua portuguesa, distribuídos em 11 números em quatro volumes anuais correspondentes.

Como resultado, encontramos 161 referências aos textos de Bakhtin e o Círculo, com tendência para uma maior circulação das seguintes obras: Os gêneros do discurso (BAKHTIN, 2016), Teoria do romance I: A estilística (BAKHTIN, 2015) e Marxismo e filosofia da linguagem. Problemas fundamentais do método sociológico na ciência da linguagem (VOLÓCHINOV, 2017); nesta ordem de frequência os textos mais referidos dentro de cada obra são, respectivamente, Os gêneros do discurso em Bakhtin (2016), O discurso no romance em Bakhtin (2015) e Partes I e II em Volóchinov (2017). A razão para o foco deste artigo no entendimento da tensão em compreensão e avaliação decorre do fato de os dois termos aparecerem constantemente nos capítulos destacados das três obras.

Estabelecido o recorte para este artigo, colocamos, então, a questão de quais obras e edições utilizarmos. Optamos pela utilização das edições mais recentes das obras em circulação no Brasil por terem sido traduzidas diretamente da língua russa, aproximandonos mais do texto original.

\section{TENSÃO}

Parece-nos que a questão da tensão e produção de sentidos nas relações humanas não é algo novo nem restrito a um ou outro autor. Sousa Santos (2014) reflete acerca dos sentidos produzidos no embate entre valores globalizados, advindos de culturas centrais, e valores localizados, presentes em culturas periféricas. $O$ autor entende que a globalização acontece em vários níveis por meio da concentração de valores por pequenos grupos de poder. Esses valores concentrados expandem-se para outros centros periféricos sempre em via de mão única, onde entram em tensão com os valores circulantes localmente, o que provoca uma mudança, nem sempre para melhor, das formas locais de expressão. Em outras palavras, nos centros periféricos, os sentidos produzidos na interação entre valores globais e valores locais são decorrentes de um tenso processo dado

\footnotetext{
${ }^{3}$ Volume 12, números 1 a 3 (2017), totalizando 23 artigos publicados, distribuídos em 7 artigos nos números 1 e 2 (cada um); e 9 artigos no número 3

Volume 13, números 1 a 3 (2018), totalizando 21 artigos publicados, distribuídos em 7 artigos nos números 1 e 3 (cada um); e 8 artigos no número 2.

Volume 14, números 1 a 4 (2019); totalizando 26 artigos publicados, distribuídos em 6 artigos nos números 1 e 4 (cada um); e 7 artigos nos números 2 e 3 (cada um).

Volume 15, número 1 (primeiro trimestre de 2020), totalizando 6 artigos publicados.

4 Os artigos estão disponíveis no portal da Bakhtiniana. Revista de Estudos do Discurso em https://revistas.pucsp.br/bakhtiniana/about/editorialPolicies\#focusAndScope Acesso em mar. 2020; e também no portal do Scielo - Scientific Electronic Library Online em https://www.scielo.br/scielo.php?script=sci_home\&lng=pt\&nrm=iso Acesso em mar. 2020.
} 
pelo embate de valores importados com os valores locais. O resultado tende ao apagamento dos valores circulantes localmente em favor de outros valores que apontam para os centros de poder.

Para o autor, o conhecimento, tratado como valor de mercadoria nas sociedades contemporâneas, passa por esse mesmo tenso movimento de produção de sentidos, pois a sociedade divide-se entre aqueles que produzem conhecimentos - e, portanto, participam de uma forma ou de outra dos movimentos globais - e aqueles que, alijados dessa produção de conhecimentos, tornam-se meros consumidores de conhecimento. Institui-se, assim, um espaço de tensão entre uns e outros que pode ser preenchido pela tradução intercultural (SOUSA SANTOS, 2014), que significa o preenchimento desse tenso espaço pelo diálogo entre diferentes grupos de perspectivas diferentes na tentativa da compreensão dos diferentes pontos de vista. Desse modo, cria-se uma espécie de ponte entre perspectivas conflitantes, entre grupos sociais e de interesses distintos com o objetivo da interação entre valores e o favorecimento da descoberta de outros meios de produção de conhecimentos que possam favorecer a inclusão de grupos cujo conhecimento é considerado de menor ou nenhum valor.

Rancière (1996), por sua vez, reflete acerca da tensão na compreensão do sentido do termo democracia, porque, para o autor, essa discussão não pode ser feita em oposição a outra forma de governo considerado antagônico. A tensão no sentido desse termo está nele mesmo, que concentra em seu interior valores correspondentes a dois polos antagônicos ou opostos, que oferecem dois pontos de vista distintos acerca do mesmo evento, isto é, acerca do valor de democracia. Partindo de uma reflexão acerca do sentido de democracia na Grécia antiga, origem desse conceito no mundo ocidental, o autor lembra que essa forma de construção política implica uma diferença qualitativa clara entre aqueles que participavam ativamente do processo democrático - e, portanto, podiam ter a palavra e decidir realmente sobre os destinos da comunidade - e aqueles que, apesar de viverem na mesma democracia grega, não tinham voz e, portanto, não participavam da tomada de decisões. Em outras palavras, de um lado existia o cidadão grego com plenos direitos políticos, ou seja, com voz e corpo na sociedade grega, e, de outro, as mulheres, os escravos e os conquistados que, de alguma forma, participavam da sociedade grega por meio do comércio, da troca de mercadorias, da produção agrícola etc., mas não possuíam voz, apenas corpo.

Essa diferença de valores é a base para toda a constituição das sociedades democráticas contemporâneas e está na origem de todas as formas de interação política nessas sociedades. Isso quer dizer que em todas as microrrelações existentes entre os sujeitos participantes das sociedades democráticas há um ponto de tensão na produção de sentidos entre aqueles que possuem voz e corpo e aqueles que somente possuem corpo. Para Rancière (1996), essa tensão é constitutiva de todas as instituições democráticas, portanto não pode ser desfeita: os sentidos produzidos pelos valores circulantes nesse espaço político sempre apontam para esse desequilíbrio. A possibilidade de confronto de valores por meio da voz daquele que só tem corpo é possível apenas por meio da expressão artística, vista como única maneira de se pensar o impensável, o novo, o diferente. Os valores estéticos propostos pela arte entram em embate com os valores políticos estabilizados e aceitos como verdadeiros. Nesse sentido, a arte funciona como um movimento político em tensão com o estritamente político, oferecendo um espaço de construção de novos sentidos por meio da crítica ao que se entende como estabelecido. 
Foucault (2017), por sua vez, trata da tensão nos valores circulantes nas relações permeadas pelo dizer a verdade a alguém. Para tanto, parte dos seguintes pontos de reflexão: o que é, de quem é e para quem é a verdade? Que condições de linguagem garantem ou permitem a veridicção? Para o autor, o dizer a verdade implica uma imbricação dos eixos de pessoa, espaço e tempo; ou seja, alguém diz uma verdade a um outro alguém em determinado espaço específico em um momento adequado para que isso aconteça. O conceito de verdade torna-se instável e fluido, pois depende do movimento sempre contínuo desses eixos. Os valores presentes nessa relação de instabilidade e fluidez são vistos da perspectiva de quatro condições fundamentais que instituem uma tensa relação entre falante e ouvinte. A primeira condição é a cumplicidade entre aquele que diz a verdade e aquele que a aceita, assumindo as consequências decorrentes desse dizer e desse ouvir a verdade. A segunda condição necessária é a confiança mútua que se institui entre quem diz a verdade a alguém e quem ouve esta verdade, pois a verdade só pode ser dita em um ambiente adequadamente confiável e seguro para ambos os participantes. A terceira condição é a coragem de dizer a verdade e de ouvir a verdade, pois ao assumirem os riscos de uma verdade, ambos se posicionam corajosamente como responsáveis pelo que foi dito. A quarta condição é a legitimação, isto é, para que haja a possibilidade de se construir uma verdade é necessário que não somente o falante diga sua verdade, mas também que o interlocutor concorde e aceite o que fora dito como verdadeiro. Para Foucault (2017), o que é importante nesse encontro é o fato de que tanto falante quanto ouvinte saem modificados em decorrência da ressignificação dos valores de verdade tanto para um quanto para outro.

Brait (2019) traz um viés discursivo ao sentido de tensão ${ }^{5}$, tratando-o como embate entre duas dimensões discursivas acerca do período em que se instalou a ditadura no Brasil. A primeira dimensão discursiva é a dos discursos oficiais que tentam, de uma maneira ou de outra, deixar ao passado o que é passado por meio do apagamento das identidades dos muitos desaparecidos durante a ditadura militar. A segunda dimensão, que se opõe discursivamente à anterior, diz respeito aos discursos não-oficiais, de resistência, constituindo-se de narrativas perdidas ou ocultas acerca dos desaparecidos que tentam, por meio de algum escape, desarticular os discursos oficiais circulantes.

Funcionando em interação com os discursos oficiais, os discursos de resistência atuam como forças centrífugas que promovem uma espécie de desequilíbrio nas forças centrípetas que constituem as vozes da oficialidade. A prosa literária caracteriza-se como um viés dessas correntes discursivas de resistência que se opõem discursivamente aos discursos oficiais. Por meio dela, principalmente, circulam discursos organizados de forma a constituir um corpo de sentido que oferece um olhar em direção à descentralização verboideológica.

\footnotetext{
${ }^{5}$ Em pesquisa no Scielo - Scientific Electronic Library Online (scielo.org.br) acerca do termo tensão associado a Bakhtin, encontramos 8 artigos entre os anos de 2001 e 2019. Como parâmetros de pesquisa, estipulamos, primeiramente, que o termo tensão deveria explicitamente aparecer no artigo juntamente com a teoria de Bakhtin e o Círculo. As discussões nos artigos giram em torno do embate entre dois centros de sentido, o que não somente parece coerente com a própria teoria de Bakhtin e o Círculo, em que a palavra é uma arena de lutas (VOLÓCHINOV, 2017), mas também aponta para os sentidos acerca de tensão discutidos nesta seção. Para este artigo, discutiremos o artigo de Brait (2019) publicado em setembro de 2019 pela aproximação temporal com o momento de produção deste artigo.
} 
Por meio da análise de duas obras que são parte de uma trilogia, a autora aponta para os valores que constituem o todo dessas obras e que se colocam como valores em estado de tensão em relação aos valores oficiais. Para tanto, focaliza os aspectos relativos ao paratexto das obras, pois entende que esses aspectos representam uma intervenção direta do autor na própria obra, estabelecendo um diálogo direto entre autor e leitor, oferecendo pistas ao interlocutor de como relacionar-se com a obra. O resultado disso é transformação da obra de ficção em mais um documento, fragmento-versão, de resistência discursiva, promovendo um embate constituído pelos documentos oficiais e resquícios de memória quase apagadas de pessoas que sofreram na luta de resistência à ditadura.

\section{COMPREENSÃO E AVALIAÇÃO}

Para as reflexões apresentadas a respeito das obras selecionados para este artigo, estabelecemos as siglas TR1 para Bakhtin (2015), OGD para Bakhtin (2016) e MFL para Volóchinov (2017). Dividimos esta seção em quatro partes, apenas por uma questão didática, mas as partes inter-relacionam-se em decorrência do todo orgânico da obra, sendo elas: compreensão e avaliação como tensão no signo ideológico, compreensão e avaliação como tensão na comunicação discursiva, compreensão e avaliação como tensão na língua viva e compreensão e avaliação como tensão no ângulo de visão.

Compreensão e avaliação como tensão no signo ideológico não somente referemse ao signo ideológico como palavra circulante entre pelos menos dois participantes de uma interação, mas também dizem respeito ao embate da palavra como arena de lutas na consciência de cada um. Não importa se o signo ideológico que invade a consciência é um signo novo ou não, pois os sentidos sempre sofrerão alterações ou deslocamentos em decorrência do movimento constante dos eixos de espaço, tempo e pessoa. A compreensão do signo ideológico na consciência ocorre em dois estágios, produzindo sentidos por meio da tensão: 1. apreensão do signo na consciência e consequente produção de sentidos; 2. validação desse sentido no sistema ideológico vigente. A avaliação, por sua vez, implica o retorno do signo à circulação com novas cores em decorrência do posicionamento do falante ${ }^{6}$ em relação ao auditório visado.

Primeiramente, torna-se necessário dizer que o termo compreensão aponta para a característica relacional e responsiva do signo ideológico. Isso significa que o signo ideológico em sua natureza dialógica "ocorre na relação deste com outros signos já conhecidos; em outras palavras, a compreensão responde ao signo e o faz também com signos” (MFL, p. 95). Essas duas características estão presentes não somente nas interações ocorridas entre dois interlocutores posicionados concretamente no mundo, mas também na consciência de cada um. O signo ideológico funciona externamente como mediador de interações, circulando no mundo em palavras trocadas em diálogo, mas refere-se também a um processo mais complexo de produção de sentidos que se estabelece na consciência individual.

\footnotetext{
${ }^{6}$ Durante as discussões apresentadas nesta seção, utilizaremos falante e ouvinte para nos referirmos aos participantes de uma interação, com o objetivo de sermos coerentes com os capítulos das obras em discussão aqui. Utilizaremos, contudo, quando necessário, interlocutores no plural para expressar a relação entre falante e ouvinte em estado de diálogo. Utilizaremos também interlocutores para a referência aos outros que falam em um enunciado.
} 
A produção de sentidos na consciência decorre de dois tensos movimentos internos no psiquismo daquele a quem a palavra se dirige. O primeiro movimento acontece no embate entre o signo externo e os signos internos. O signo externo, premente de resposta, penetra na consciência do ouvinte entrando em embate com os signos internos circulantes e responsivos presentes nessa mesma consciência. Do confronto entre o signo externo e os signos circulantes internamente aparecem novos sentidos como respostas a esse encontro. Assim é o movimento que garante a vida do signo ideológico, que se renova constantemente à medida que outros sentidos lhe são agregados. O signo ideológico "se desenvolve no processo de renovação de sua compreensão, vivência e assimilação, ou seja, em sua inserção contínua no contexto interior" (MFL, p. 128).

O segundo movimento na compreensão do signo ideológico ocorre em relação ao conjunto de valores ideológicos presentes no sistema ideológico vigente, isto é, "compreender significa perceber o signo dentro de um sistema ideológico correspondente" (MFL, p. 131). O sistema ideológico existe na consciência individual composta por signos ideológicos que apontam para valores válidos e existe também como sistema ideológico exterior, circulando externamente à consciência do indivíduo, dando sentido à realidade. Isso significa que os valores que compõem o sistema ideológico encontram-se vivos e circulantes tanto na consciência de cada membro de uma comunidade quanto externamente a cada consciência, no mundo exterior, discursivo e repleto de valores.

O movimento de validação do novo sentido do signo ideológico acontece quando o sentido é confrontado com os valores ideológicos circulantes internamente na consciência. Nesse instante, ocorre um reposicionamento de valores dentro desse sistema ideológico interno pelo embate entre sentido e valores circulantes. O reposicionamento de valores no sistema ideológico da consciência implica também um deslocamento no sistema ideológico exterior, porque o signo ideológico funciona como um pêndulo que se renova quando penetra na consciência e renova os valores ideológicos quando é externalizado.

Dito de outro modo, o sistema ideológico é composto por palavras, signos ideológicos por natureza, circulantes internamente à consciência, compondo os valores no sistema ideológico interno presente na consciência do indivíduo. A renovação dos valores presentes no sistema ideológico exterior ocorre após a validação dos valores ideológicos ocorridos na consciência, no momento em que o ouvinte torna-se falante, $o$ que mantém o signo ideológico vivo e sempre atualizado, pois, para se manter em circulação no mundo, o signo ideológico "precisa imergir no universo dos signos subjetivos interiores, obter tonalidades subjetivas" (MFL, p. 138), ganhar novas nuances de sentido.

A avaliação, que "possui um papel criativo nas mudanças das significações" (MFL, p. 237), torna-se extremamente relevante nesse contexto de renovação dos valores ideológicos. Após passar pelo processo de renovação de valores na consciência como recepção ativa, o signo ideológico, repleto de novas nuances de sentido, é devolvido à circulação externa, no instante em que o ouvinte torna-se falante. Ocorre que esse instante não é despido de significação; ao contrário, as possiblidades avaliativas são tantas quantas são as possibilidades determinadas pelo posicionamento de cada um no tempo e no espaço. 
A entoação expressiva da palavra tem o papel de dar sentido ao ponto de vista do falante frente aos interlocutores, considerando os valores ideológicos circulantes. Isso significa que "na maioria dos casos a entonação é definida pela situação mais próxima, e muitas vezes pelas suas circunstâncias efêmeras" (MFL, p. 233), o que implica novos deslocamentos de sentido para o signo ideológico. O signo ideológico, já colorido com novos tons advindos da consciência, passa por outras instâncias de produção de sentidos em interações, constituindo um movimento incessável de embate e renovação, "para não se transformar em uma relíquia de museu que é respeitada, mas incompreendida" (MFL, p. 138).

Compreensão e avaliação como tensão na comunicação discursiva referem-se à interação constituída entre dois participantes, podendo ocorrer como um diálogo em que duas pessoas conversam, caracterizando-se como a "forma mais simples e clássica da comunicação discursiva" (OGD, p. 34). Pode também ocorrer em maneiras mais refinadas de interação "nos campos da comunicação cultural (científica ou artística) de organização complexa" (OGD, 34). O falante, tendo em vista um auditório que pode ser real ou imaginado, fisicamente presente ou distanciado, orienta seu enunciado, estabelecendo um projeto discursivo que não somente inclui uma possível resposta prevista, mas também e, ao mesmo tempo, responde a outros interlocutores situados em outros tempos e espaços.

Em todo enunciado há diversos centros de tensão pressionando a produção de sentidos em decorrência de orientações responsivas direcionadas não somente ao ouvinte direto ou visado, mas também a outros interlocutores presentes na constituição do próprio enunciado. Para esta discussão, percebemos pelo menos três aspectos que exercem pressão no enunciado: a orientação responsiva interna, que direciona o projeto discursivo do falante a uma provável resposta esperada; a resposta ativa do próprio falante porque no enunciado produzido circulam outras respostas a interlocutores anteriores; e a avaliação que implica uma reação valorativa do locutor em direção ao próprio objeto de sentido do enunciado produzido.

Quanto à orientação responsiva interna, primeiro aspecto do enunciado que exerce tensão sobre a produção de sentidos, podemos defini-la como a expectativa do falante em relação a seu ouvinte para que este movimente-se em direção a uma resposta ativa já nas primeiras palavras produzidas no enunciado. Considerando que "o ouvinte, ao perceber e compreender o significado (linguístico) do discurso, ocupa simultaneamente em relação a ele uma ativa posição responsiva" (OGD p. 25), podemos entender que essa expectativa do falante significa que há, dentro dos limites de um gênero do discurso, graus variados de liberdade na construção de seu enunciado. Essa liberdade pode acontecer na escolha de palavras, ou na seleção de termos e expressões e até na escolha de uma ordem sintática, visando a uma reação do ouvinte. A tensão na produção de sentidos focaliza-se nessa expectativa por meio das escolhas enunciativas.

Como consequência de o falante não esperar de seu ouvinte "uma compreensão passiva [...] mas uma resposta, uma concordância, uma participação, uma objeção, uma execução, etc” (OGD, p. 26), na comunicação discursiva o ouvinte, em reação ao enunciado, pode iniciar a "compreensão desde o seu início, às vezes literalmente a partir da primeira palavra do falante" (OGD, p. 25). A resposta ativa a esse enunciado pode ser 
imediata como em um diálogo entre dois interlocutores frente a frente; ou "pode permanecer de quando em quando como compreensão ativa silenciosa" (OGD, p. 25), em que uma resposta concreta pode vir a se manifestar de formas variadas futuramente.

Quanto ao aspecto referente à resposta ativa do falante na construção de um enunciado, temos de considerar que esse mesmo falante foi, em algum momento anterior, um ouvinte ativo de outros interlocutores. Como consequência disso, por meio de uma "compreensão ativa de efeito retardado" (OGD, p. 25), o falante responde tardiamente a esses outros enunciados em seu próprio enunciado. A tensão ocorre no enunciado projetado porque o falante orienta-o também a esses outros interlocutores a quem responde ativamente em reação tardia. Em outras palavras, o enunciado encontra-se em constante estado responsivo não somente porque foi projetado para a compreensão ativa de um auditório previsto ou esperado, mas também porque implica do falante uma reação a outros interlocutores. Porque um dia foi ouvinte ativo de discursos direcionados a ele, o falante responde ativamente a esses enunciados produzidos, organizando essa reação em seu próprio enunciado.

O aspecto avaliativo compõe a construção de sentidos estabelecida pela compreensão ativa na comunicação discursiva a partir de dois pontos de vista: a discursividade do objeto de sentido e a escolha do gênero do discurso. A discursividade do objeto de sentido pode ser entendida como uma reação do falante em direção ao objeto de sentido do enunciado. O objeto de sentido de todo enunciado está atravessado de discursos anteriores, encontrando-se "já difamado, contestado, avaliado, envolvido ou por uma fumaça que o obscurece ou, ao contrário, pela luz de discursos alheios já externados a seu respeito" (TR1, p. 48). O falante posicionado em seu tempo e espaço, visando a um auditório, participante direto ou não da comunicação discursiva estabelecida, volta-se ao objeto de seu enunciado e estabelece uma relação de sentido por meio da entonação valorativa direcionada a esse objeto, como reação aos discursos que atravessam esse objeto e como orientação ao auditório visado. Desse modo, o elemento expressivo, que "é a relação subjetiva emocionalmente valorativa do falante com o conteúdo do objeto e do sentido do seu enunciado" (OGD, p. 47), instaura mais uma camada de sentido na orientação do enunciado, constituindo mais um elemento direcionado ao auditório.

A expressividade decorrente da escolha do gênero do discurso acontece, de um lado, em relação ao problema da escolha do gênero do discurso no projeto discursivo do falante. E, de outro lado, na escolha das palavras que compõem o enunciado em determinado gênero do discurso escolhido. No que concerne ao problema da escolha dos gêneros do discurso no projeto discursivo do falante, os gêneros possuem certo grau de impessoalidade. Isso quer dizer que, apesar de serem mais plásticos do que as formas da língua, os gêneros do discurso possuem uma estabilidade relativa, o que significa que cada gênero do discurso possui uma expressividade típica decorrente das possibilidades oferecidas em cada campo da atividade humana.

Mesmo assim, a escolha de determinado gênero do discurso constitui-se no primeiro viés expressivo resultante da vontade discursiva individual na orientação do enunciado dentro de uma esfera de atuação humana. As possibilidades expressivas decorrentes da escolha dos gêneros do discurso em determinado campo de atuação humana dependem do contato do falante com a realidade imediata. Disso resultam 
variações nas possibilidades expressivas de acordo com o grau de coerção do gênero do enunciado e da possibilidade dada ao falante de escolher as palavras, as expressões e a ordem sintática no enunciado, entre outras coisas. Essa decisão somente pode ser tomada quando o falante direciona seu olhar não somente para seu auditório concreto ou imaginado, mas também para o contexto concreto de circulação de valores em que a interação ocorre. O que é importante notar é que essas palavras, expressões etc., escolhidas pelo falante na construção de seu enunciado constituíram "enunciados do outro sobre o mesmo tema, aos quais respondemos, com os quais polemizamos" (OGD, p. 58), isto é, aos quais respondemos ativamente.

Podemos resumir a questão da avaliação da seguinte forma: o falante, em seu projeto discursivo, posicionado em seu tempo e espaço, sob a coerção de determinado gênero, estabelece uma relação valorativa com o objeto de sentido do enunciado. Ao mesmo tempo, as palavras e orações utilizadas nesse enunciado já passaram por outras enunciações, de onde o falante retirou-as. Por isso, essas palavras e orações estão repletas de outras "atitudes responsivas a outros enunciados de dado campo de comunicação" (OGD, p. 57). Desse modo, a entoação expressiva não somente encontra-se na relação do falante com o objeto de sentido de seu enunciado, mas também está presente na escolha de palavras de um enunciado que podem ser às vezes mais e às vezes menos livres dependendo das coerções do gênero do discurso.

Compreensão e avaliação como tensão em relação à forma da língua e seu uso como língua viva podem ser entendidas como um embate entre os valores que visam à estabilidade e ao controle social e cultural e os valores que visam à renovação e à evolução social e histórica. As forças centrípetas estabelecem um tipo estático de compreensão, associada à identidade de formas, enquanto as forças centrífugas associam-se à compreensão ativa, germe da resposta ativa. O problema da forma e do uso da língua aponta para a confluência de pelo menos três eixos de sentido concorrentes e concomitantes: o eixo da estabilidade, o eixo da língua viva e o eixo da acentuação.

$\mathrm{O}$ eixo estabilidade refere-se à percepção instantânea de que existe uma língua comum entre falante e ouvinte. Isso se dá nos vários níveis linguísticos - por exemplo, "os significados lexicográficos neutros das palavras da língua asseguram para ela a identidade e a compreensão mútua de todos os seus falantes" (OGD, p. 53). As formas abstratas da língua garantem um tipo de "compreensão passiva, isto é, uma compreensão da palavra em que a resposta ativa é eliminada de antemão por princípio" (MFL, p. 186). Dessa perspectiva, não há tensão na produção de sentidos, há apenas a garantia do mesmo por meio da manutenção das formas abstratas que asseguram um "maximum de compreensão mútua em todos os campos da vida ideológica” (TR1, p. 40).

O eixo da língua viva refere-se ao momento em que há um movimento em direção à compreensão ativa, quando o ouvinte, ao ouvir um enunciado, coloca-o em um contexto discursivo por onde circulam outros discursos assemelhados, pois "no geral a tarefa da compreensão não se reduz ao reconhecimento da forma usada, mas à sua compreensão em um contexto concreto" (MFL, p. 178). Ocorre que essa inserção não é um movimento simples de encaixe de discursos, pois implica um embate entre o enunciado apreendido e as correntes de discursos presentes na consciência do ouvinte para um campo de atuação humana. Disso decorre uma outra nova percepção do ouvinte acerca da realidade 
discursiva em que se insere. $\mathrm{O}$ eixo da fala viva implica tanto a percepção do ouvinte acerca de um certo contexto discursivo válido para ele, quanto uma orientação do enunciado apreendido em direção aos discursos que circulam nesse contexto, com vistas a um movimento de readequação dos sentidos produzidos pelas correntes discursivas circulantes.

Esse movimento assemelha-se ao signo ideológico, pois, primeiramente, a adequação de sentidos ocorre de forma interna, na consciência do ouvinte, onde os contextos são readequados, e, posteriormente, de forma externa, quando o ouvinte tornase falante. Internamente, os sentidos relativos aos contextos alteram-se, alterando a percepção do ouvinte acerca da realidade que o cerca. Quando o ouvinte torna-se falante, já alterado por meio da experiência ocorrida internamente, a percepção da realidade modifica-se, refletindo-se nos enunciados produzidos e interferindo na percepção do auditório visado.

O eixo da acentuação constitui o momento posterior ao momento da língua viva, ou seja, após os enunciados terem integrado a corrente de discursos na consciência do ouvinte, implicando o momento da construção da resposta ativa em que o ouvinte poderá tornar-se falante. O processo pode ser descrito da seguinte forma: os enunciados na comunicação discursiva existem para o ouvinte, em primeiro lugar, como palavras de outros e, por isso, repletas de ecos de outros enunciados. Esses enunciados, com seus tons valorativos advindos desses outros, são reavaliados por um processo de assimilação mais ou menos ativa e criativa por parte do ouvinte, pois, ingressados em correntes de discursos presentes na consciência, são constantemente reorientados, de acordo com a intenção discursiva, com o projeto discursivo dentro de um gênero específico, e segundo a orientação avaliativa que se quer dar ao enunciado. Isso quer dizer que a acentuação dá expressividade aos enunciados no momento que o enunciado é projetado em direção a um novo ouvinte no momento da fala.

Compreensão e avaliação como tensão no ângulo de visão referem-se aos sentidos produzidos ou visados em decorrência da diferença de posicionamento de cada um dos participantes de uma interação nos eixos de espaço e de tempo. A esse respeito, percebemse três vieses de sentido que se cruzam, instaurando uma complexidade no instante do encontro entre falante e ouvinte. O primeiro viés relaciona-se ao problema do contexto em que falante e ouvinte se posicionam, porque esse contexto está repleto de valores sociais que exercem pressão sobre o sentido do enunciado. O segundo viés trata do embate decorrente de distintos ângulos de visão dos participantes, isto é, o posicionamento de cada um dos participantes no tempo e no espaço implica diferentes campos de visão e, portanto, diferentes perspectivas acerca do mesmo objeto. E o terceiro viés relaciona-se à expressividade do enunciado direcionado ao ouvinte, pois a tentativa de previsão de reação do outro na construção de qualquer enunciado torna-o expressivo na expectativa de uma resposta ativa.

O viés relacionado ao contexto refere-se à percepção dos participantes de uma interação de que pertencem a um contexto comum de valores circulantes tanto do ponto de vista mais imediato e concreto quanto do ponto de vista mais distante e abstrato relacionado ao tempo histórico. Nesse caso, o entendimento acerca do compartilhamento de um espaço contextual comum provoca, por parte dos participantes, respostas que 
tendem a deixar claro o pertencimento a esse terreno comum (VOLÓCHINOV, 2019). Ocorre que esse contexto é mais complexo do que o simples espaço físico onde se encontram falante e ouvinte, porque qualquer lugar está sempre atravessado por discursos e, consequentemente, pelos valores sociais que esses discursos carregam consigo. Afirmamos, assim, que o contexto possui dois lados: um lado estável e concreto, comum a todos, e outro lado, que interessa para a produção de sentidos, discursivo e repleto de valores. Trataremos especificamente desse segundo tipo de contexto.

O contexto discursivo apresenta dois vieses: de um lado, os discursos que atravessam o contexto circulam no mundo real; de outro lado e ao mesmo tempo, esses discursos são percebidos como pertencentes a determinado contexto em decorrência de também circularem na consciência individual. Isso quer dizer que o contexto discursivo existe por meio da confluência entre os discursos circulantes em correntes de discursos na consciência do falante ao mesmo tempo que esses discursos circulam concretamente no mundo exterior por meio das interações presentes em cada situação concreta com a qual falante e ouvinte têm contato.

Em relação ao funcionamento do contexto na consciência individual, compreensão como tensão ocorre responsivamente por meio do encontro entre os enunciados circulantes externamente que penetram na consciência do ouvinte e os enunciados relativos circulantes internamente na consciência discursiva do mesmo ouvinte que apontam para aspectos contextuais comuns. Disso decorre que novos sentidos para um determinado contexto são produzidos na confluência entre o externo e o interno, o que significa que "em cada palavra de um enunciado compreendido, acrescentamos como que uma camada de nossas palavras responsivas" (MFL, p. 232). Decorre daí que a compreensão, ação interna de produção de sentidos, torna-se tanto mais complexa quanto maior for a quantidade e a qualidade de "palavras responsivas" (MFL, p. 232): outros enunciados circulantes na consciência de cada um acerca de contextos aproximados e que já foram respondidos ativamente.

Ao mesmo tempo que se caracteriza como uma ação interna, esse movimento de compreensão ativa é também uma ação externa de produção de sentidos porque a qualidade e a quantidade de contato com enunciados alheios que foram internalizados em referência a certo contexto implicam diferentes graus de percepção em relação ao mundo exterior. Em outras palavras, os contextos discursivos, resultantes de processos de compreensão decorrentes da internalização de enunciados alheios, são posteriormente respondidos ativamente por meio de reações variadas. No que se refere à quantidade e qualidade de palavras contextualizadas, pode-se afirmar que "quanto maior for o seu número, quanto mais essenciais elas forem, tanto mais profunda e essencial será a compreensão" (MFL, p. 232) contextual.

O viés relacionado ao ângulo de visão trata do problema das distintas perspectivas decorrentes da variação no posicionamento de cada um dos participantes de uma interação no espaço e no tempo, pois o ângulo de visão de cada um implica um olhar distinto em relação a valores visados. Ao produzir um enunciado, o falante assume uma posição no eixo espaço-tempo em relação a seu auditório. O ângulo de visão decorrente desse posicionamento permite a esse falante ver todo um conjunto de valores que provavelmente não estão completamente acessíveis ao auditório a quem a fala é 
direcionada. Por sua vez, o ângulo de visão do auditório também difere do ponto de vista do falante. A compreensão acontece durante a ação de orientação dos enunciados por parte do falante em direção aos ouvintes. A compreensão direciona-se não somente ao enunciado produzido, mas também aos sentidos decorrentes dos valores transmitidos pelo ângulo de visão do falante, inacessível ao olhar desse ouvinte.

Podemos afirmar que a compreensão ativa do ouvinte extrapola a orientação contextual comum e vai em direção ao processamento de valores visados pelo falante, decorrentes da perspectiva advinda de um ângulo de visão específico. Esse ângulo de visão repleto de valores, direcionado ao ouvinte, implica "novos aspectos da existência que passam a integrar o horizonte de interesses sociais abordados pela palavra e pelo pathos humano (MFL, p. 237)". A tensão estabelece-se no embate entre valores circulantes no contexto discursivo comum entre falante e ouvinte e entre os valores visados no horizonte valorativo do falante que penetram na consciência do ouvinte. $\mathrm{O}$ resultado é um choque de sentidos entre o que é comum e o que é visado, cujo resultado retorna ao contexto comum em forma de um deslocamento de sentidos e de reposicionamento constante nos espaços contextuais em que circulam enunciados relacionados.

O viés avaliativo, que compõe esse processo de compreensão, refere-se à expectativa do falante acerca de uma resposta esperada por parte do auditório a quem dirige a fala. Essa expectativa, que pode ser "sentida como resistência ou apoio" (TR1, p. 54) a ser dada pelo ouvinte a quem a palavra é dirigida, abre caminho para a inserção do ouvinte no próprio enunciado. $\mathrm{O}$ falante passa a trabalhar o enunciado "em território alheio, no campo aperceptivo do ouvinte" (TR1, p. 56), enriquecendo o enunciado com o oferecimento de possibilidades expressivas abertas ao falante na tentativa do vislumbre de uma resposta ativa. $O$ falante, sentindo que na sua frente há um complexo caminho discursivo que se apresenta na imagem construída do outro, volta-se a seu enunciado e passa a colori-lo expressivamente visando a "alma do ouvinte como seu campo aperceptivo" (TR1, p. 54).

A orientação expressiva do enunciado por parte do falante em direção a seu ouvinte extrapola o objeto de sentido e se torna uma aposta do próprio falante na projeção no enunciado de valores pertencentes a um possível horizonte de valores decorrente do ponto de vista do ouvinte. Isso promove um tom estilístico no enunciado com o objetivo do autorreconhecimento, pelo ouvinte, do que é dito. A expressividade baseia-se naquilo que o falante imagina serem os valores visados pelo ouvinte, "aqui não é o objeto que serve como arena do encontro, mas o horizonte subjetivo do ouvinte" (TR1, p. 56). Como resultado, o enunciado torna-se expressivo em seu conjunto porque os valores são continuamente trabalhados pelo falante na tentativa de alcançar a perspectiva do ouvinte, para que este reaja dentro dos limites oferecidos pela previsão inicial.

A expectativa do falante em relação a esse movimento de orientação expressiva em direção ao ouvinte é que este produza sentido de maneira que implique uma alteração de "seu lugar na unidade do horizonte valorativo (MFL, p. 237)". O tom estilístico do enunciado, dessa maneira, está diretamente ligado ao contexto discursivo visado e externo ao próprio enunciado, e também aos elementos advindos dessa expectativa acerca do horizonte de valores do outro, o que torna a expressividade do enunciado um aspecto 
intersubjetivo. A orientação expressiva do enunciado pelo falante pode ser entendida como uma "política interna do estilo (a combinação de seus elementos) [...] determinada por sua política externa (pela relação com a palavra do outro)" (TR1, p. 57).

Chegamos ao fim desse percurso de sentido sobre compreensão e avaliação. Portanto, podemos dar um acabamento relativo à discussão. Afirmamos com clareza que em todas as instâncias de sentido em que compreensão faz-se presente, seu sentido é construído em tensão tendo como polo oposto de significação a resposta ativa. A compreensão é um estágio de internalização de palavras, de enunciados, de valores relacionado diretamente à instância de recepção em que o ouvinte é visado como alguém que vai reagir de alguma maneira ao enunciado produzido. Na preparação da resposta ativa, a compreensão estabelece uma conexão de sentido entre diferentes perspectivas e pontos de vista em decorrência dos variados posicionamentos decorrentes do movimento dos eixos pessoa, espaço e tempo. Decorrem desse movimento constante, sentidos novos e prontos para retornarem ao mundo.

A avaliação, por sua vez, caracteriza-se também como uma instância de produção de sentidos anterior à resposta ativa como um processo de preparação para a externalização de um enunciado, referindo-se ao instante de produção do enunciado, quando o ouvinte assume o papel de falante. O ouvinte, após ter passado pela produção de sentidos por meio da compreensão, inicia os procedimentos para a externalização de uma resposta ativa, tornando-se falante e tendo como orientação um auditório visado. A avaliação é uma previsão acerca da posição do interlocutor no espaço-tempo com o objetivo de estabelecer o máximo de compreensão. O locutor estabelece uma conexão de sentido com o ouvinte por meio de nuances de expressividade, tons estilísticos, etc, gerando "a centelha da expressão" (OGD, p. 51).

\section{CONSIDERAÇÕES FINAIS}

$\mathrm{Na}$ introdução deste artigo, apresentamos o problema relacionado à compreensão e avaliação do ponto de vista da tensão na produção de sentidos. Nossa proposta foi entender, primeiramente, o sentido de tensão e, posteriormente, discutir os pontos de tensão no que diz respeito à compreensão e avaliação em relação aos capítulos pertencentes às três obras de Bakhtin e o Círculo. Após o direcionamento metodológico do trabalho, fizemos um breve percurso teórico em que observamos que o sentido de tensão significa embate entre, pelo menos, dois pontos de vista distintos, assim como descrito na metáfora da faísca elétrica resultante do contato entre dois polos opostos (VOLÓCHINOV, 2017).

No tratamento dos textos de Bakhtin e o Círculo, percebemos que o sentido de compreensão implica uma reação à palavra do outro, que se reverte posteriormente em uma ação concreta como resposta ativa. A compreensão pode ser definida como uma ação que orienta o ouvinte a uma escuta ativa e situada, e a avaliação corresponde a um posicionamento do falante em direção a seu próprio enunciado, colorindo-o de várias formas, com vistas a uma previsão de expectativas de resposta ativa por parte do futuro ouvinte. 
Não podemos terminar o artigo sem voltar a reflexão para a relação entre o pesquisador e seu texto, já que o processo que se estabeleceu reflete o movimento entre compreensão e avaliação tratado teoricamente neste artigo. De um lado, há o aspecto da compreensão ativa do pesquisador em direção à teoria e, de outro lado, a avaliação dessa interação e as entonações expressivas resultantes que produzem as reflexões trazidas por este artigo e que, consequentemente, implicarão outras instâncias de compreensão e responsividade futuras. Como resultado desse processo de compreensão ativa, no gênero relativamente estável que podemos denominar artigo científico a escolha das palavras, a ordenação das orações, a ordem das seções etc. implicam um ponto de vista avaliativo do pesquisador em relação a uma resposta direcionada ao auditório visado.

O direcionamento do olhar do pesquisador sobre a teoria implica uma tensa relação entre os valores advindos do posicionamento do pesquisador no espaço-tempo e os valores circulantes na teoria como enunciado concreto. Do encontro, sentidos foram produzidos, porém o olhar posicionado de outro pesquisador em outro tempo e outro espaço trará outra perspectiva de tratamento dos dados da teoria, pois "a palavra como a conhecemos reflete sensivelmente as mudanças mais sutis da existência social" (BAKHTIN, 2016, p. 112). Isso garante uma fluidez nos sentidos tratados e a consequente evolução das pesquisas, "pois um processo de formação só pode ser apreendido com a ajuda de outro processo também de formação" (VOLÓCHINOV, 2017, p. 232).

A dinamicidade da produção de sentidos constitui o motor das mudanças sociais, às vezes lentas, outras vezes rápidas, porque aponta para um constante devir, um constante estado de incompletude, o que garante a continuidade das reflexões em decorrência da abertura a outros processos de compreensão e avaliação. A tensão constitui-se no motor da produção de sentidos, trazendo instabilidade e movimento na nas reflexões teóricas em oposição às tentativas de reprodução do mesmo. As reflexões teóricas que visam a um universo fechado, estável e homogêneo correspondem ao movimento de alguém que "na verdade quer acender uma lâmpada desligando-a da corrente elétrica (VOLÓCHINOV, 2017, p. 233).

\section{REFERÊNCIAS}

AGAMBEN, G. The Signature of all Things - On Method. Zone Book: New York, 2009.

BAKHTIN, M. A teoria do romance I: A estilística. Tradução, prefácio, notas e glossário: Paulo Bezerra. Organização da edição russa: Serguei Botcharov e Vadim Kójinov. São Paulo: Ed. 34, [1977] 2015.

BAKHTIN, M. Os gêneros do discurso. Organização, tradução, posfácio e notas: Paulo Bezerra. Notas da edição russa: Serguei Botcharov. São Paulo: Martins Fontes, [1979] 2016.

BRAIT, B. Discursos de resistência: do paratexto ao texto. Ou vice-versa? Alfa, São Paulo, v. 63, n. 2, p. 243-263, 2019.

FOUCAULT, J. A coragem da verdade - O governo de si e dos outros II - Cursos no Collège de France (1983-1984). Tradução: Eduardo Brandão. São Paulo: Martins Fontes, 2017.

GROSFOGUEL, R. Racismo/Sexismo epistémico, Universidades Occidentalizadas e Los Quatro Genocidios/Espistemicidios Del Largo Siglo XVI. Tabula Rasa, Bogotá - Colombia, n. 19, p. 31-58, jul.dec. 2013.

MORIN, E. Introdução ao pensamento complexo. Tradução: Dulce Matos. Lisboa: Instituto Piaget, 1991. 
RANCIÈRE, J. O desentendimento. Política e Filosofia. Tradução: Ângela Leite Lopes. São Paulo: Editora 34, 1996.

SOUSA SANTOS, B. Um discurso sobre as ciências. São Paulo: Cortez, 2008.

SOUSA SANTOS, B. Epistemologies of the South: Justice Against Epistemicide. London: Paradigm Publishers, 2014.

VOLÓCHINOV, V. (Círculo de Bakhtin). Marxismo e filosofia da linguagem - Problemas Fundamentais do Método Sociológico na Ciência da Linguagem. Tradução, notas e Glossário: Sheila Grillo e Ekaterina Vólkova Américo. Ensaio Introdutório: Sheila Grillo. São Paulo: Editora 34, [1929] 2017.

VOLÓCHINOV, V.N. (Círculo de Bakhtin). A palavra na vida e a palavra na poesia. Ensaios, artigos, resenhas e poemas. Organização, tradução, ensaio introdutório e notas: Sheila Grillo e Ekaterina Vólkova. São Paulo: Editora 34, [1926] 2019.

VOLOSINOV, V.N. Marxism and the Philosophy of Language. Translated by Ladislav Matejk and I.R. Titunik. Cambridge, Massachusetts, London (England): Harvard University Press, [1929] 1973.

VOLOSHINOV, V.N. El signo ideológico y la filosofía del lenguaje. Traducción del inglés de Rosa María Rússovic. Buenos Aires: Ediciones Nueva Visión, [1929]1976.

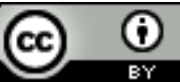

Este texto está licenciado com uma Licença Creative Commons Atribuição 4.0 Internacional. 